\title{
Metabolismo oxidativo de leucócitos em animais infectados pelo Vírus da Leucemia Bovina
}

\author{
Oxidative burst of leukocytes from bovine leukemia Virus-Infected Cattle
}

\author{
Milton Ricardo AZEDO ${ }^{1}$; Cristina de Oliveira MASSOCO ${ }^{2}$; Maiara Garcia BLAGITZ ${ }^{1}$; Fernando \\ Nogueira de SOUZA ${ }^{1}$; Fabio Celidônio POGLIANI ${ }^{1}$; Fernando José BENESI ${ }^{1}$; Alice Maria Melville \\ Paiva DELLA LIBERA ${ }^{1}$
}

${ }^{1}$ Departamento de Clínica Médica da Faculdade de Medicina Veterinária e Zootecnia da Universidade de São Paulo, São Paulo SP, Brasil

${ }^{2}$ Departamento de Patologia da Faculdade de Medicina Veterinária e Zootecnia da Universidade de São Paulo, São Paulo - SP, Brasil

\begin{abstract}
Resumo
A infecção pelo vírus da leucemia bovina (VLB) leva ao desenvolvimento de linfocitose persistente (LP) ou linfossarcomas, principalmente em rebanhos bovinos leiteiros. Entretanto, os eventos que induzem tais manifestações ou o efeito da infecção na função das diferentes populações de leucócitos são pouco conhecidos. Avaliou-se o efeito da infecção pelo VLB na produção intracelular de peróxido de hidrogênio $\left(\mathrm{H}_{2} \mathrm{O}_{2}\right)$ em leucócitos circulantes, mensurada pela fluorescência produzida pela diclorodihidrofluoresceína, utilizando-se de citometria de fluxo. As células foram obtidas de cinco vacas soronegativas; cinco vacas infectadas pelo VLB, alinfocitóticas; e cinco vacas infectadas, manifestando LP. Verificou-se que a infecção pelo VLB não altera a porcentagem de leucócitos circulantes produzindo $\mathrm{H}_{2} \mathrm{O}_{2}$, com ou sem prévio estímulo por adição in vitro: de 12-miristato 13-acetato de forbol (PMA); de lipopolissacarídeos de Escherichia coli (LPS); ou Staphylococcus aureus. Todavia, a produção de $\mathrm{H}_{2} \mathrm{O}_{2}$ em leucócitos de animais apresentando LP, com ou sem estímulo, foi menor que aquela verificada em leucócitos de animais soronegativos e de animais soropositivos alinfocitóticos. Os estímulos aumentaram a porcentagem de leucócitos produzindo $\mathrm{H}_{2} \mathrm{O}_{2}$ e a produção intracelular média em animais soronegativos ou naqueles infectados alinfocitóticos. Contudo, em leucócitos de vacas soropositivas manifestando LP, a fagocitose de $S$. aureus não elevou a porcentagem de leucócitos produzindo $\mathrm{H}_{2} \mathrm{O}_{2}$. Também, apenas a adição de PMA elevou a produção intracelular de $\mathrm{H}_{2} \mathrm{O}_{2}$ em leucócitos de fêmeas soropositivas manifestando LP. Concluiu-se que bovinos infectados pelo VLB, manifestando LP, apresentam menor produção intracelular de $\mathrm{H}_{2} \mathrm{O}_{2}$, demonstrando vulnerabilidade funcional refletida por imunossupressão.
\end{abstract}

Palavras-chave: Radicais livres. Leucócitos. Deltaretrovírus. Leucose enzoótica bovina. Bovinos.

\begin{abstract}
Widespread Bovine Leukemia Virus (BLV) infection leads to persistent lymphocytosis (PL) or lymphosarcoma, mainly in dairy herds. Nevertheless, neither the sequence of events that conducts to these symptoms, nor the effect of infection on function of different leukocyte populations, is well known. We evaluated the effect of BLV infection on immune response of cows through the analysis of hydrogen peroxide $\left(\mathrm{H}_{2} \mathrm{O}_{2}\right)$ intracellular production of circulating leukocytes after in vitro stimuli with phorbol-12-myristate-13-acetate (PMA), Escherichia coli lipopolysaccharides (LPS), or Staphylococcus aureus. Cells were obtained from five BLV-non infected cows, five BLV-infected, non-lymphocytotic cows, and five BLV-infected cows with PL, and analyzed by flow cytometry. Intracellular production of $\mathrm{H}_{2} \mathrm{O}_{2}$ was measured by dichlorodihydrofluorescein diacetate dependent fluorescence. Results showed that BLV infection does not alter the percentage of $\mathrm{H}_{2} \mathrm{O}_{2}$-producing circulating leukocytes $\left(\mathrm{H}_{2} \mathrm{O}_{2}-\mathrm{PCL}\right)$, with or without previous stimuli. However, the average of $\mathrm{H}_{2} \mathrm{O}_{2}$ intracellular production, with or without previous stimuli, in leukocytes obtained from cows with PL was smaller than those from cells obtained from BLV-negative cows and from BLV-infected, non-lymphocytotic cows. Moreover, stimuli increased $\mathrm{H}_{2} \mathrm{O}_{2}$ intracellular production and the percentage of $\mathrm{H}_{2} \mathrm{O}_{2}$-PCL obtained from BLVnegative cows and from BLV-infected, non-lymphocytotic cows. Conversely, neither phagocytosis of $S$. aureus and stimulus with LPS increases $\mathrm{H}_{2} \mathrm{O}_{2}$ intracellular production, nor phagocytosis increases the percentage of $\mathrm{H}_{2} \mathrm{O}_{2}$-PCL, when leukocytes were obtained from cows with PL. Thus, results show that BLV-infected cattle, with PL, have an impaired $\mathrm{H}_{2} \mathrm{O}_{2}$ intracellular production, demonstrating functional vulnerability reflected by immunosuppression.
\end{abstract}

Keywords: Free radicals. Leukocytes. Deltaretrovirus. Enzootic bovine leukosis. Cattle.

Correspondência para:

Alice Maria Melville Paiva Della Libera

Departamento de Clínica Médica

Faculdade de Medicina Veterinária e Zootecnia

Universidade de São Paulo
Av. Prof. Dr. Orlando Marques de Paiva, 87 - Cidade Universitária

05508-000 - São Paulo, SP

Recebido em: 16/05/2011

Aprovado em: 18/04/2012 


\section{Introdução}

A Leucose Enzoótica Bovina (LEB), infecção causada pelo vírus da Leucemia Bovina (VLB), é considerada um profícuo modelo animal para o estudo da influência dos vírus oncogênicos linfotrópicos na resposta imunitária do hospedeiro ${ }^{1}$. Compartilhando arranjo estrutural e genético com os deltaretrovírus humanos ${ }^{2}$, associados a leucemia de células $\mathrm{T}$ e linfoma em adultos, ambos desenvolvem doença crônica e proliferação das células-alvo envolvendo células e mediadores imunitários. No mundo, apenas alguns países conseguiram sua erradicação ${ }^{3}$. No Brasil, todavia, sua ocorrência vem sendo relatada em quase todos os Estados ${ }^{4}$. A transmissão do agente ocorre, principalmente, por meio de transferência iatrogênica de linfócitos infectados pelo uso indiscriminado de instrumentos sem a devida desinfecção ${ }^{5}$. Assim, posto que os animais são submetidos a manipulações mais intensas, é relatada maior prevalência em rebanhos leiteiros e de alta produção ${ }^{6}$.

O VLB infecta, principalmente, linfócitos $\mathrm{B}$, integrando-se, em lugares dispersos, ao seu genoma ${ }^{7}$. Infectado, o bovino pode apresentar-se com sorodiagnóstico positivo e alinfocitótico, ou seja, sem a presença de linfocitose persistente (LP); ou com sorodiagnóstico positivo manifestando LP, caracterizada por uma elevação crônica no número de linfócitos circulantes e encontrada em cerca de 30\% dos bovinos infectados ${ }^{8}$. Cerca de $10 \%$ dos animais infectados podem, ainda, desenvolver linfossarcomas, caracterizados por infiltração mononuclear em órgãos ricos em tecido linfóide, comumente os linfonodos, o baço, o coração, o útero, o abomaso, o fígado e/ou os rins, tendo ou não previamente apresentado LP. Os sintomas relatados ${ }^{9}$ tornam-se evidentes quando as neoplasias invadem os diferentes tecidos e são dependentes do órgão envolvido. Deste modo, perdas econômicas diretas decorrentes da infecção são devidas à redução da produção, à condenação das carcaças, aos custos com a reposição mais precoce e ao aumento dos cus- tos com serviços veterinários, apenas na pequena proporção de bovinos que apresentam linfossarcomas. Perdas indiretas são decorrentes da restrição no comércio de animais ou de seus produtos ${ }^{10}$. Não obstante, a sequência de eventos que leva a alterações do número de linfócitos circulantes ou ao desenvolvimento tumoral, decorrentes da infecção pelo VLB, é pouco conhecida. Do mesmo modo, o efeito da infecção e dos mecanismos envolvidos na gênese da LP e do linfossarcoma na função de outras populações de leucócitos, podendo contribuir para a instalação ou manutenção de um estado de imunossupressão, também não está claro.

A proteção provida por mecanismos imunitários inatos, primeira barreira especificamente desenvolvida contra a penetração de patógenos em um organismo, desempenha papel crucial na defesa contra doenças infecciosas. Células envolvidas neste mecanismo possuem habilidade em reconhecer e destruir antígenos estranhos ou células infectadas, sem a necessidade de ter havido um prévio encontro com tais antígenos. Para tanto, tais células utilizam-se da fagocitose e de atividades dependentes de oxigênio, relacionadas à explosão respiratória, funções fundamentais na destruição e eliminação do agente invasor ${ }^{11}$. Alterações nas funções inerentes a estas populações celulares podem ser induzidas, por exemplo, pela interação de fatores exógenos, tais como drogas, por injúrias físicas ou por infecções intracelulares, característica das infecções virais. Tais alterações, ocorrendo nas diversas populações de leucócitos relacionadas à resposta contra patógenos, podem levar o animal a um estado depletivo na proteção fornecida pelo aparato imunitário, caracterizando um quadro de imunossupressão. De fato, em animais com LEB, quando manifestando LP, verificou-se, em prévio estudo ${ }^{12}$, que há alteração na função fagocítica de leucócitos circulantes.

Apesar da ampla variedade de métodos utilizando citometria de fluxo para avaliar o metabolismo oxidativo de células humanas, usados também para a ava- 
liação da resposta imunitária de equinos ${ }^{13,14}$, poucos estudos foram realizados empregando-os para analisar leucócitos de bovinos ${ }^{15,16,17}$. Sobretudo, não foram encontrados estudos avaliando tal função em bovinos infectados pelo VLB. Assim, o presente estudo avaliou o efeito da infecção pelo VLB sobre a imunidade inata de fêmeas bovinas por meio da análise da produção intracelular de peróxido de hidrogênio $\left(\mathrm{H}_{2} \mathrm{O}_{2}\right)$ por leucócitos circulantes obtidos de animais naturalmente infectados pelo VLB, frente diferentes estímulos in vitro, utilizando-se da citometria de fluxo.

\section{Material e Método}

Foram obtidos leucócitos circulantes, de acordo com os princípios éticos de utilização animal da Comissão de Bioética da Faculdade de Medicina Veterinária e Zootecnia da Universidade de São Paulo (protocolo no 973/2006), de três grupos de cinco fêmeas bovinas: um apresentando sorodiagnóstico negativo para LEB; outro de fêmeas naturalmente infectadas pelo VLB, alinfocitóticas; e um terceiro, de fêmeas infectadas manifestando LP.

$\mathrm{O}$ agrupamento fora realizado segundo os resultados do teste de Imunodifusão em Agar Gel (Antígeno para diagnóstico de Leucose Enzoótica Bovina - Produção: Laboratório TECPAR, Curitiba, PR; Controle de qualidade: MAPA), conforme indicações do fabricante; e de leucogramas seriados com intervalo de 90 dias, considerando-se, como referência, os dados obtidos por Távora ${ }^{18}$. Os animais, da raça Holandês Preto e Branco, em lactação, com idade variando entre 30 e 72 meses (média $=46$ meses; desvio padrão $=10,1$ meses), eram oriundos de um único rebanho, localizado no Município de Santa Rita do Passa Quatro, no Estado de São Paulo. Ainda, apresentavam bom estado nutricional, não haviam sido submetidos a tratamento com glicocorticóides nos últimos 30 dias, assim como não se encontravam em fase puerperal, fatores estes que poderiam interferir na resposta imunitária.
De cada animal, foi coletado, por venopunção coccígea, utilizando-se sistema a vácuo, $10 \mathrm{~mL}$ de sangue em tubo siliconizado com heparina, mantidos sob refrigeração até a realização dos ensaios. Para cada amostra, cinco tubos para citometria foram identificados com letras (A, B, C, D e E) e com o número ou nome do animal, os quais receberam tampão fosfato-salino (PBS), a $4^{\circ} \mathrm{C}$, em quantidade suficiente para um volume final de $1 \mathrm{~mL}$ por tubo (conforme esquema apresentado na Figura 1), seguidos de $100 \mu \mathrm{L}$ do sangue coletado. Para a avaliação da produção intracelular de $\mathrm{H}_{2} \mathrm{O}_{2}$, por citometria de fluxo, nos tubos "B", "C", "D" e "E" foram também adicionados $200 \mu \mathrm{L}(60 \mu \mathrm{g})$ de Diacetato de 2,7-Diclorodihidrofluoresceína (DCFH-DA Molecular Probes $^{\mathrm{rm}}$, Eugene, OR; nº cat. C1157). Como estímulos in vitro para a produção intracelular $\mathrm{de}_{2} \mathrm{O}_{2}$, no tubo "C", foram adicionados $200 \mu \mathrm{L}$ de Staphylococcus aureus (cepa ATCC 25923, na concentração aproximada de 2,4 x $10^{9}$ bactérias/mL de PBS); no tubo " $\mathrm{D}$ ", foram adicionados $100 \mu \mathrm{L}$ (100 ng) de 12-miristato 13-acetato de forbol (PMA - Phorbol 12-Myristate 13-Acetate - PMA - Sigma ${ }^{\mathrm{Tx}}$, St. Louis, MO; $\mathrm{n}^{\mathrm{o}}$. cat. P8139); e no tubo "E", $100 \mu \mathrm{L}$ (100 ng) de lipopolissacarídeos (LPS) de Escherichia coli (Escherichia coli - cepa O55:b5 - Sigma ${ }^{\text {Tx }}$, St. Louis, MO; $n^{\circ}$. cat. L-3129). Após a adição dos estímulos, as preparações foram incubadas em banho-maria, a uma temperatura de $37^{\circ} \mathrm{C}$, sob ligeira agitação. Depois de 30 minutos de incubação, foram adicionados, em cada tubo, $2 \mathrm{~mL}$ de solução, a $4^{\circ} \mathrm{C}$, de ácido etilenodiamino tetra-acético (EDTA) (3 $\mathrm{mM})$. A seguir, os tubos foram centrifugados por 10 minutos, a 400 x G, a $4^{\circ} \mathrm{C}$. Para a lise hipotônica dos eritrócitos, após desprezar-se o sobrenadante, foram adicionados, a cada alíquota, $2 \mathrm{~mL}$ de $\mathrm{NaCl}$ a $0,2 \%$, a $4^{\circ} \mathrm{C}$, e, esperados 20 segundos, $2 \mathrm{~mL}$ de $\mathrm{NaCl}$ a $1,6 \%$, a $4^{\circ} \mathrm{C}$, para a recomposição da isotonicidade da solução. Após nova centrifugação por 10 minutos, a 400 x G, a $4^{\circ} \mathrm{C}$, repetiu-se a lise de eritrócitos. Após desprezarse, mais uma vez, o sobrenadante, em cada tubo foram adicionados $500 \mu \mathrm{L}$ de $\mathrm{PBS}$, a $4^{\circ} \mathrm{C}$, para a análise. 


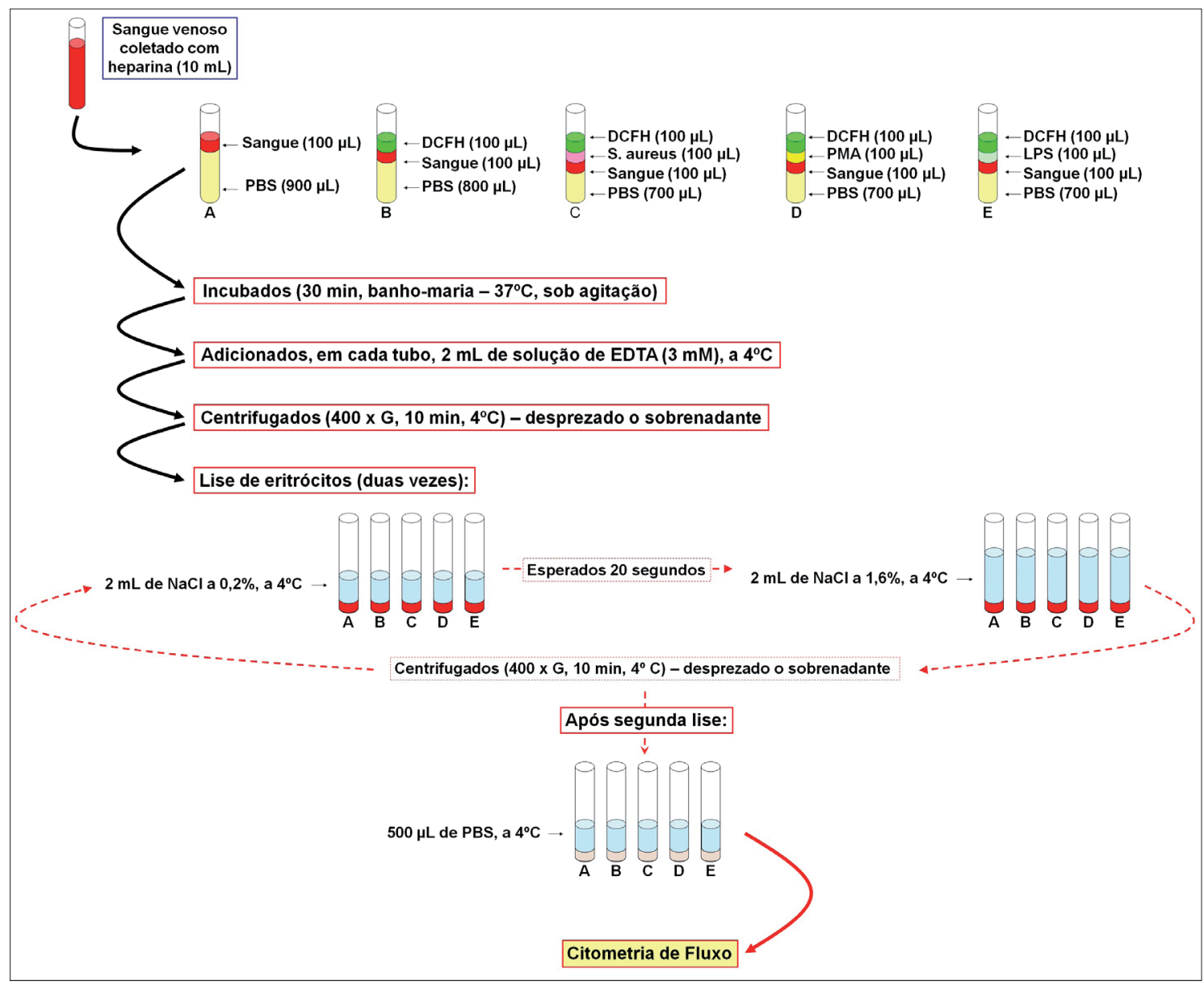

Figura 1 - Resumo esquemático do ensaio de produção intracelular de peróxido de hidrogênio adotado no presente estudo - São Paulo - 2012

Dez mil eventos de cada amostra foram adquiridos e analisados em citômetro de fluxo FACSCalibur (Becton Dickinson Immunocytometry System ${ }^{\text {Th}}$, San Diego, CA), por meio do programa Cell Quest Pro ${ }^{\text {iv }}$. Foram avaliadas a porcentagem de células emitindo fluorescência e a intensidade média de fluorescência obtida após a oxidação, pelo peróxido de hidrogênio intracelular, do DCFH em DCF. Como controle da fluorescência basal das células analisadas, o aparelho foi calibrado com o tubo $\mathrm{A}$, no qual não havia a adição de DCFH-DA. Foi verificada a normalidade da distribuição dos resultados, utilizando-se o teste de AndersonDarling, e sua homoscedasticidade, utilizando-se o teste F. Para a avaliação das diferenças entre as médias dos resultados obtidos, foram feitos os testes de análise de variância (ANOVA) e de Tukey-Kramer, empregando-se o programa estatístico MINITAB ${ }^{\oplus}$, versão 14.1 (GlobalTech Informática ${ }^{\text {Ts }}$, Belo Horizonte, MG). Para todos os resultados, foram consideradas significantes as análises que apresentaram $\mathrm{p} \leq 0,05$.

\section{Resultados e Discussão}

Avaliou-se, neste estudo, a influência da infecção pelo VLB na atividade oxidativa in vitro de leucócitos bovinos na fase alinfocitótica da enfermidade e na presença de LP, utilizando-se a análise por citometria de fluxo. Neste contexto, a técnica utilizada mostrou ser rápida, demandando pequeno volume sanguíneo, além de não exigir a prévia separação das populações 
leucocitárias, corroborando o que fora destacado por Vowells et al. ${ }^{19}$. Ademais, Smits, Burvenich e Heyneman $^{15}$ ressaltaram que o uso de sangue total (como realizado no presente trabalho), ao invés de populações de leucócitos previamente isoladas, minimiza os riscos de contaminação por toxinas possivelmente presentes em reagentes utilizados no isolamento celular, tais como substâncias utilizadas para separação celular por gradiente de densidade, ou mesmo por meio da adição de soro animal.

No ensaio em que se avaliou a produção de radicais oxidativos por leucócitos sem prévio estímulo in vitro, verificou-se que, em média, 30,60\% dos leucócitos obtidos das fêmeas selecionadas apresentavam produção de $\mathrm{H}_{2} \mathrm{O}_{2}$ (Tabela 1). Apesar da ausência de estímulo in vitro, supõe-se que esta produção deu-se em decorrência do constante estímulo in vivo a que estão submetidas as células sanguíneas e que, em qualquer ensaio por meio do qual seja verificada a produção intracelular de espécies reativas de oxigênio (EROs), exista, em maior ou menor grau, uma porcentagem de leucócitos produzindo $\mathrm{H}_{2} \mathrm{O}_{2}$, sobretudo quando estas células são obtidas de animais mantidos em condições naturais. Realmente, Flaminio et al. ${ }^{13}$ verificaram atividade oxidativa espontânea em fagócitos sanguíne- os de equinos, separados previamente por gradiente de densidade, em ensaio sem a adição de estímulos in vitro. Resultados semelhantes obtiveram Walrand et al. ${ }^{20}$, avaliando leucócitos polimorfonucleares humanos, também previamente isolados por meio de gradiente de densidade. Apesar da maior quantidade de linfócitos circulantes em animais manifestando LP, não houve diferença na porcentagem de leucócitos que estavam produzindo $\mathrm{H}_{2} \mathrm{O}_{2}$, entre os grupos experimentais (Tabela 1). Assim, parece plausível sugerir que a infecção pelo VLB não altera a quantidade relativa de leucócitos circulantes produzindo $\mathrm{H}_{2} \mathrm{O}_{2}$, com ou sem prévio estímulo in vitro, em fêmeas bovinas. Não obstante, não foram encontrados, em pesquisas envolvendo a produção de EROs por leucócitos de bovinos, relatos acerca da porcentagem de células produzindo $\mathrm{H}_{2} \mathrm{O}_{2}$, especialmente em decorrência de que estas avaliações haviam sido realizadas após prévia separação celular ${ }^{21,22,23}$, ou apenas na população de granulócitos ${ }^{17}$.

Por sua vez, verifica-se na tabela 2 que, em leucócitos produzindo $\mathrm{H}_{2} \mathrm{O}_{2}$, a produção intracelular média (em valores arbitrários de intensidade de fluorescência do DCF), sem estímulo in vitro, em células obtidas de animais apresentando LP $(21,59)$, foi menor

Tabela 1 - Porcentagens médias ( \pm desvio padrão) ${ }^{1}$ de leucócitos sanguíneos produzindo peróxido de hidrogênio intracelular frente diferentes estímulos in vitro - São Paulo - 2012

\begin{tabular}{|c|c|c|c|c|c|c|}
\hline \multirow{2}{*}{ Estímulo $^{3}$} & \multicolumn{3}{|c|}{ Grupo $^{2}$} & \multirow{2}{*}{ C.V. } & & \multirow{2}{*}{$\begin{array}{c}\text { Total } \\
(n=15)\end{array}$} \\
\hline & $\begin{array}{c}\text { SN } \\
(n=5)\end{array}$ & $\begin{array}{c}\mathrm{AL} \\
(\mathrm{n}=5)\end{array}$ & $\underset{(n=5)}{\mathbf{L P}}$ & & & \\
\hline Sem estímulo & $33,00^{\mathrm{Aa}}( \pm 19,66)$ & $18,80^{\mathrm{Aa}}( \pm 16,68)$ & $40,00^{\mathrm{Aa}}( \pm 8,60)$ & 2,98 & $\mathrm{p}>0,05$ & $30,60^{A}( \pm 17,16)$ \\
\hline PMA & $62,80^{\mathrm{Ba}}( \pm 34,50)$ & $58,00^{\mathrm{Ba}}( \pm 43,80)$ & $68,60^{\mathrm{Ba}}( \pm 9,56)$ & 9,33 & $\mathrm{p}>0,05$ & $63,13^{\mathrm{B}}( \pm 30,60)$ \\
\hline LPS & $57,20^{\mathrm{Ba}}( \pm 10,47)$ & $46,60^{\mathrm{Ba}}( \pm 23,00)$ & $52,20^{\mathrm{Ba}}( \pm 14,72)$ & 2,63 & $\mathrm{p}>0,05$ & $52,00^{\mathrm{B}}( \pm 16,25)$ \\
\hline S. aureus & $56,40^{\mathrm{Ba}}( \pm 25,30)$ & $42,60^{\mathrm{Ba}}( \pm 28,40)$ & $43,40^{\mathrm{Aa}}( \pm 5,77)$ & 4,62 & $\mathrm{p}>0,05$ & $47,47^{\mathrm{AB}}( \pm 21,58)$ \\
\hline \multirow[t]{2}{*}{ C.V. } & 6,22 & 9,56 & 2,16 & & & 1,92 \\
\hline & $p=0,008$ & $\mathrm{p}=0,001$ & $\mathrm{p}=0,018$ & & & $\mathrm{p}=0,005$ \\
\hline
\end{tabular}

${ }^{1}$ Valores com letras minúsculas divergentes em uma mesma linha indicam diferença entre grupos, com $\mathrm{p}$ indicado na penúltima coluna. Valores com letras maiúsculas divergentes em uma mesma coluna indicam diferença intragrupos, com $\mathrm{p}$ indicado na última linha. Variáveis analisadas pelos testes estatísticos ANOVA e de Tukey-Kramer, com significância para $\mathrm{p} \leq 0,05$. C.V.: coeficiente de variação

${ }^{2} \mathrm{SN}$ : vacas soronegativas para leucose enzoótica bovina (LEB); AL: vacas soropositivas para LEB, alinfocitóticas; LP: vacas soropositivas para LEB, apresentando linfocitose persistente

${ }^{3}$ PMA: 12-miristato 13-acetato de forbol; LPS: lipopolissacarídeos de Escherichia coli 
Tabela 2 - Intensidade média de fluorescência (em valores aleatórios) da diclorofluoresceína ( \pm desvio padrão) ${ }^{1}$ verificada em leucócitos sanguíneos de vacas, frente diferentes estímulos in vitro - São Paulo - 2012

\begin{tabular}{|c|c|c|c|c|c|c|}
\hline \multirow[b]{2}{*}{ Estímulo $^{3}$} & \multicolumn{3}{|c|}{ Grupo $^{2}$} & \multirow[b]{2}{*}{ C.V. } & & \multirow{2}{*}{$\begin{array}{c}\text { Total } \\
(n=15)\end{array}$} \\
\hline & $\underset{(n=5)}{S N}$ & $\underset{(n=5)}{\mathrm{AL}}$ & $\underset{(n=5)}{\mathbf{L P}}$ & & & \\
\hline Sem estímulo & $34,25^{\mathrm{Aa}}( \pm 7,92)$ & $32,17^{\mathrm{Aa}}( \pm 3,69)$ & $21,59^{\mathrm{Ab}}( \pm 3,63)$ & 58,50 & $\mathrm{p}=0,007$ & $29,34^{\mathrm{A}}( \pm 7,65)$ \\
\hline PMA & $97,53^{\mathrm{Ba}}( \pm 3,49)$ & $86,80^{\mathrm{Ba}}( \pm 26,90)$ & $28,81^{\mathrm{Bb}}( \pm 21,65)$ & 132,23 & $\mathrm{p}<0,001$ & $71,06^{\mathrm{B}}( \pm 36,35)$ \\
\hline LPS & $55,79^{\mathrm{Ca}}( \pm 16,87)$ & $48,53^{\mathrm{Ca}}( \pm 6,04)$ & $22,25^{\mathrm{Ab}}( \pm 2,96)$ & 86,67 & $\mathrm{p}=0,001$ & $42,19^{\mathrm{A}}( \pm 17,80)$ \\
\hline S. aureus & $68,00^{\mathrm{Ca}}( \pm 22,50)$ & $51,67^{\mathrm{Ca}}( \pm 13,85)$ & $21,93^{\mathrm{Ab}}( \pm 1,98)$ & 89,26 & $\mathrm{p}=0,002$ & $47,18^{\mathrm{A}}( \pm 24,27)$ \\
\hline \multirow[t]{2}{*}{ C.V. } & 828,75 & 621,31 & 17,41 & & & 661,74 \\
\hline & $\mathrm{p}<0,001$ & $\mathrm{p}<0,001$ & $\mathrm{p}=0,005$ & & & $\mathrm{p}<0,001$ \\
\hline
\end{tabular}

${ }^{1}$ Valores com letras minúsculas divergentes em uma mesma linha indicam diferença entre grupos, com p indicado na penúltima coluna. Valores com letras maiúsculas divergentes em uma mesma coluna indicam diferença intragrupos, com p indicado na última linha. Variáveis analisadas pelos testes estatísticos ANOVA e de Tukey-Kramer, com significância para p $\leq 0,05$. C.V.: coeficiente de variação

${ }^{2} \mathrm{SN}$ : vacas soronegativas para leucose enzoótica bovina (LEB); AL: vacas soropositivas para LEB, alinfocitóticas; LP: vacas soropositivas para LEB, apresentando linfocitose persistente

${ }^{3}$ PMA: 12-miristato 13-acetato de forbol; LPS: lipopolissacarídeos de Escherichia coli

( $\mathrm{p}=0,007)$ que aquela verificada em células provenientes de animais soronegativos $(34,25)$ e de animais soropositivos alinfocitóticos $(32,17)$. Em estudo prévio $^{12}$, verificou-se que, em bovinos infectados pelo VLB, manifestando LP, a porcentagem média de células realizando fagocitose de Staphylococcus aureus foi menor que aquela observada em amostras de animais soronegativos e de animais alinfocitóticos, fato justificável pela menor quantidade relativa de células com propriedades fagocíticas na circulação daqueles animais. Entretanto, a intensidade média de fagocitose mensurada nos leucócitos de animais manifestando LP também foi menor que a constatada em leucócitos de animais alinfocitóticos e de animais soronegativos. Em conjunto, estes resultados indicam que as alterações envolvidas na origem ou na manutenção do estado de LP prejudicam os mecanismos imunitários inatos, posto que leucócitos de bovinos infectados pelo VLB, manifestando LP, possuem menor capacidade fagocítica e menor produção intracelular de $\mathrm{H}_{2} \mathrm{O}_{2}$, ERO necessária para a destruição dos patógenos fagocitados.

Watson et al. ${ }^{24}$ já haviam observado que a adição de substâncias estimuladoras da atividade oxidativa proporciona uma avaliação mais acurada desta atividade, sobretudo, quando da utilização de pequena quantidade de células e/ou de células com baixo índice de produção. Deste modo, foram adicionados estímulos in vitro às células recém coletadas, antes do ensaio de produção de $\mathrm{H}_{2} \mathrm{O}_{2}$. Verificou-se que (Tabela 1) a porcentagem de células produzindo $\mathrm{H}_{2} \mathrm{O}_{2}$ aumentou $(\mathrm{p}=0,005)$ com a adição de PMA $(63,13 \%)$ e com LPS $(52,00 \%)$. No entanto, o estímulo por meio da fagocitose de $S$. aureus não aumentou a porcentagem de células produzindo $\mathrm{H}_{2} \mathrm{O}_{2}(47,47 \%)$, comparando-se com o ensaio sem prévio estímulo (30,60\%), quando foram avaliadas as células obtidas de todos os animais. Por sua vez, este aumento foi verificado quando avaliados apenas os leucócitos de animais soronegati$\operatorname{vos}(\mathrm{p}=0,008)$ e aqueles de animais infectados alinfocitóticos $(\mathrm{p}=0,001)$ demonstrando, deste modo, que o estímulo pela fagocitose de $S$. aureus não altera a porcentagem de leucócitos produzindo $\mathrm{H}_{2} \mathrm{O}_{2}$ apenas em ensaios que contenham amostras sanguíneas de animais com LP. Tais resultados permitem advertir que, em ensaios em que se busca uma maior proporção de células produzindo $\mathrm{H}_{2} \mathrm{O}_{2}$ mediante estímulo in vitro por fagocitose de $S$. aureus, como aqueles realizados por Flaminio et al. ${ }^{13}$ e por Massoco e Palermo Neto ${ }^{14}$, utilizando-se de células de equinos, e, mais especifi- 
camente, por Smits, Burvenich e Heyneman ${ }^{15}$ e por Kampen, Tollersrud e Lund ${ }^{17}$, analisando leucócitos bovinos, deve-se, de antemão, constatar se as amostras sanguíneas foram obtidas de animais infectados pelo VLB, manifestando LP.

Conquanto, também após os diferentes estímulos in vitro, a produção intracelular média de $\mathrm{H}_{2} \mathrm{O}_{2}$ de leucócitos obtidos de animais apresentando LP foi menor que aquela verificada em células provenientes de animais soronegativos e de animais soropositivos sem LP (Tabela 2). Os estudos conduzidos por Werling et al. ${ }^{25}$, Pyeon, O’Reilly e Splitter ${ }^{26}$ e, posteriormente, por Yakobson et al. ${ }^{27}$, Amills et al. ${ }^{28}$, Debacq et al. ${ }^{29}$ e Konnai et al. ${ }^{30,31}$ sugerem que alterações na quantidade e na atividade de citocinas envolvidas na resposta imunitária, aliadas a uma mudança no perfil de citocinas relacionado à resposta celular (Th-1) para aquele encontrado na resposta humoral (Th-2), podem estar relacionadas com a progressão da enfermidade para o surgimento da LP ou de linfossarcomas. Supõe-se que tal alteração no perfil de citocinas, nomeadamente a maior produção de fator de necrose tumoral (TNF)- $a$ e o desbalanço na expressão de receptores celulares de TNF, observados por Kabeya et al. ${ }^{32}$, pode induzir maior persistência viral através do aumento da taxa de proliferação dos linfócitos B infectados e, deste modo, conduzir o hospedeiro à LP. Entretanto, muito embora a dinâmica celular ainda necessite ser mais bem elucidada em bovinos manifestando LP, o aumento do número de linfócitos circulantes poderia ser gerado por alterações no potencial apoptótico das células infectadas, induzidas pela ação do agente viral. Contudo, os resultados de diferentes estudos divergem. Enquanto os trabalhos conduzidos por Konnai et al. ${ }^{30,31}$ verificaram uma maior proliferação em células mononucleares de sangue periférico (CMSP) de animais manifestando LP, Debacq et al. ${ }^{29}$ observaram menor índice de morte celular, aliado a uma taxa de proliferação também menor, em linfócitos B de animais infectados, com LP. Mais recentemente, Bouzar et al. ${ }^{33}$ verificaram que linfócitos B obtidos de ovinos infectados apresentaram menores índices de apoptose in vitro. Nesse estudo, os autores observaram evidências demonstrando que baixas concentrações de EROs têm papel chave na diminuição dos índices de apoptose, induzida pela infecção pelo VLB.

De fato, as EROs estão envolvidas na regulação de uma série de processos celulares, na dependência de sua concentração intracelular. Um efeito benéfico ocorre com concentrações baixas ou moderadas e está associado com a ativação e modulação da sinalização intracelular, a defesa contra agentes infecciosos e a indução de resposta mitogênica ${ }^{34}$. No entanto, concentrações intracelulares excessivas de EROs causam dano a lipídios, proteínas e ácidos nucléicos e tornamse tóxicas para a célula ${ }^{35}$. Como defesa contra altas concentrações de EROs, a célula faz uso de diversas enzimas antioxidantes, tais como a Superóxido Desmutase, a Catalase, a Glutationa Peroxidase e a Tioredoxina. Deste modo, o estresse oxidativo é originado de um desbalanço entre a produção de EROs e a atividade antioxidante enzimática ${ }^{36}$. No estudo de Bouzar et al. ${ }^{33}$, evidenciou-se que linfócitos B infectados pelo VLB expressam altos níveis de Tioredoxina. Por outro lado, foi observada uma menor produção de Interferon (IFN)- $\gamma$ em animais manifestando $\mathrm{LP}^{37,38}$. É sabido que altas concentrações intracelulares de EROs induzem a expressão do gene que codifica a proteína quinase dependente de RNA de fita dupla (PKR) por meio da ativação do gene que codifica o IFN- $\gamma$, que, por sua vez, atua diretamente na inibição da replicação viral. Por sua vez, a PKR é um componente central na defesa contra infecções virais em virtude de seu papel na indução de apoptose em células infectadas ${ }^{39}$. Assim, a partir destas observações, deduz-se que o VLB altera os mecanismos imunitários do hospedeiro induzindo aumento nas concentrações celulares de Tioredoxina que, por sua vez, diminui as concentrações de $\mathrm{H}_{2} \mathrm{O}_{2}$. Concentrações celulares reduzidas de EROs diminuem as concentrações celulares de IFN- $\gamma$ e de 
PKR, contribuindo para a persistência viral. Como decorrência, a menor indução de apoptose contribui para a gênese da LP.

Convém observar que a ativação da atividade oxidativa promovida pelo PMA, por meio da ativação da enzima NADPH oxidase, após ativação da proteína quinase $\mathrm{C}$ (PKC), não é mediada por receptores da membrana celular e não é precedida da formação do fagolisossomo. Diverso da ativação promovida pelo PMA, o estímulo para a produção de $\mathrm{H}_{2} \mathrm{O}_{2}$ promovido pelo LPS de E. coli e pela fagocitose de S. aureus ocorre por meio da ligação a receptores da membrana plasmática dos leucócitos, atuando, deste modo, como estimulantes mais naturais da atividade oxidativa ${ }^{16}$. Neste ensejo, constatou-se, no presente estudo (Tabela 2), que o aumento na produção intracelular de $\mathrm{H}_{2} \mathrm{O}_{2}$ foi maior quando foi utilizado, como estímulo prévio, a adição de PMA. No entanto, este estu-

\section{Referências}

1. UNGAR-WARON, H.; PAZ, R.; BRENNER, J.; YAKOBSON, B.; PARTOSH, N.; TRAININ, Z. Experimental infection of calves with bovine leukemia virus (BLV): an applicable model of a retroviral infection. Veterinary Immunology and Immunopathology, v. 67, n. 2, p. 195-201, 1999.

2.SAGATA, N.; YASUNAGA, T.; TSUZUKU-KAWAMURA, J.; OHISHI, K.; OGAWA, Y.; IKAWA, Y. Complete nucleotide sequence of the genome of bovine leukemia virus: its evolutionary relationship to other retroviruses. Proceedings of the National Academy of Sciences of the United States of America, v. 82, n. 3, p. 677-681, 1985.

3. RODRIGUEZ, S. M.; GOLEMBA, M. D.; RODOLFO, H.; CAMPOS, R. H.; TRONO, K.; LEANDRO, R.; JONES, L. R. Bovine Leukemia Virus can be classified into seven genotypes: evidence for the existence of two novel clades. Journal of General Virology, v. 90, n. 11, p. 2788-2797, 2009.

4. D’ANGELINO, J. L.; GARCIA, M.; BIRGEL, E. H. Epidemiological study of enzootic bovine leukosis in Brazil. Tropical Animal Health and Production, v. 30, n. 1, p. 13-15, 1998.

5. HOPKINS, S. G.; DIGIACOMO, R. F. Natural transmission of bovine leukemia virus in dairy and beef cattle. Veterinary Clinics of North America: Food Animal Practice, v. 13, n. 1, p. 107-128, 1997.

6. OLSON, C.; BAUMGARTENER, L. E. Epizootiology of natural infection with bovine leukemia virus. Bibliotheca Haematologica, v. 43, p. 255-259, 1975.

7.SCHWARTZ, I.; BENSAID, A.; POLACK, B.; PERRIN, B.; BERTHELEMY, M.; LEVY, D. In vivo leukocyte tropism of bovine leukemia virus in sheep and cattle. The Journal of Virology, v. 68, n. 7, p. 4589-4596, 1994. do também constatou que, em leucócitos obtidos de bovinos infectados pelo VLB, manifestando LP, não ocorre aumento na produção intracelular de $\mathrm{H}_{2} \mathrm{O}_{2}$ após estímulo com LPS de E. coli e com S. aureus, indicando que a infecção interfere, também, nos mecanismos envolvidos na gênese do fagolisossomo e na conseguinte produção de EROs, caracterizando uma diminuição na resposta imune dessas células.

\section{Conclusão}

Bovinos infectados pelo vírus da leucemia bovina, manifestando linfocitose persistente, apresentam menor produção intracelular média de peróxido de hidrogênio em consequência de uma maior expressão de agentes celulares antioxidantes e por uma menor capacidade fagocítica destas células, demonstrando, deste modo, vulnerabilidade funcional refletida por imunossupressão.

8. SCHWARTZ, I.; LEVY, D. Pathobiology of bovine leukemia virus. Veterinary Research, v. 25, n. 6, p. 521-536, 1994.

9. THURMOND, M. C.; LAPUZ, G. R.; FARVER, T. B.; MANDAC, G. C. Retrospective study of four years of carcass condemnation rates for malignant lymphoma in California cows. American Journal of Veterinary Research, v. 46, n. 6 , p. 1387-1391, 1985.

10.CHI, J.; VANLEEUWEN, J. A.; WEERSINK, A.; KEEFE, G. P. Direct production losses and treatment costs from bovine viral diarrhoea virus, bovine leukosis virus, Mycobacterium avium subspecies paratuberculosis, and Neospora caninum. Preventive Veterinary Medicine, v. 55, n. 2, p. 137-153, 2002.

11.SHEPHERD, V. L. The role of the respiratory burst of phagocytes in host defense. Seminars in Respiratory Infections, v. 1, n. 2, p. 99-106, 1986.

12.AZEDO, M. R.; MASSOCO, C. O.; BLAGITZ, M. G.; SANCHES, B. G. S.; SOUZA, F. N. de; BATISTA, C. F.; SAKAI, M.; SÁ-ROCHA, L. C. de; KFOURY JUNIOR, J. R.; STRICAGNOLO, C. R.; BENESI, F. J.; DELLA LIBERA, A. M. M. P. Influência da Leucose Enzoótica Bovina na função fagocítica de leucócitos circulantes em animais manifestando linfocitose persistente. Brazilian Journal of Veterinary Research and Animal Science, v. 45, n. 5, p. 390-397, 2008.

13. FLAMINIO, M. J.; RUSH, B. R.; DAVIS, E. G.; HENNESSY, K.; SHUMAN, W.; WILKERSON, M. J. Simultaneous flow cytometric analysis of phagocytosis and oxidative burst activity in equine leukocytes. Veterinary Research Communications, v. 26, n. 2 , p. $85-92,2002$.

14. MASSOCO, C.; PALERMO-NETO, J. Effects of midazolam on equine innate immune response: a flow cytometric study. 
Veterinary Immunology and Immunopathology, v. 95, n. 1/2, p. 11-19, 2003.

15.SMITS, E.; BURVENICH, C.; HEYNEMAN, R. Simultaneous flow cytometric measurement of phagocytotic and oxidative burst activity of polymorphonuclear leukocytes in whole bovine blood. Veterinary Immunology and Immunopathology, v. 56, n. 3/4, p. 259-269, 1997.

16.KAMPEN, A. H.; TOLLERSRUD, T.; LARSEN, S.; ROTH, J. A.; FRANK, D. E.; LUND, A. Repeatability of flow cytometric and classical measurement of phagocytosis and respiratory burst in bovine polymorphonuclear leukocytes. Veterinary Immunology and Immunopathology, v. 97, n. 1/2, p. 105$114,2004$.

17.KAMPEN, A. H.; TOLLERSRUD, T.; LUND, A. Flow cytometric measurement of neutrophil respiratory burst in whole bovine blood using live Staphylococcus aureus. Journal of Immunological Methods, v. 289, n. 1-2, p. 47-55, 2004.

18.TAVORA, J. P. F. Hemograma de bovinos das raças Gir, Girolando e Holandesa criados no Estado de São Paulo: estabelecimento dos valores de referência e avaliação das influências de fatores de variabilidade raciais, etários e sexuais. 1998. 163 f. Tese (Doutorado em Clínica Veterinária) Faculdade de Medicina Veterinária e Zootecnia, Universidade de São Paulo, São Paulo, 1998.

19.VOWELLS, S. J.; SEKHSARIA， S.; MALECH, H. L.; SHALIT, M.; FLEISHER, T. A. Flow cytometric analysis of the granulocyte respiratory burst: a comparison study of fluorescent probes. Journal of Immunological Methods, v. 178 , n. 1, p. 89-97, 1995.

20.WALRAND, S.; VALEIX, S.; RODRIGUEZ, C.; LIGOT, P.; CHASSAGNE, J.; VASSON, M. P. Flow cytometry study of polymorphonuclear neutrophil oxidative burst: a comparison of three fluorescent probes. Clinica Chimica Acta, v. 331, n. 1/2, p. 103-110, 2003.

21.SCHUBERTH, H. J.; RIEDEL-CASPARI, G.; LEIBOLD, W. Flow cytometric testing of immunological effects of a phytomedicinal combination (equimun) and its compounds on bovine leucocytes. Journal of Veterinary Medicine Series A, v. 49, n. 6, p. 291-298, 2002.

22.STAKAUSKAS, R.; LEIBOLD, W.; PIESKUS, J.; MIRONOVA, L.; SCHUBERTH, H. J. Alpha-1-acid glycoprotein inhibits phorbol ester-induced but not Fc-receptor-induced generation of reactive oxygen species in bovine peripheral blood neutrophils. Journal of Veterinary Medicine Series A, v. 52 , n. 5, p. 213-218, 2005.

23. RINALDI, M.; MORONI, P.; LEINO, L.; LAIHIA, J.; PAAPE, M. J.; BANNERMAN, D. D. Effect of cis-urocanic acid on bovine neutrophil generation of reactive oxygen species. Journal of Dairy Science, v. 89, n. 11, p. 4188-4201. 2006.

24.WATSON, G. L.; SLOCOMBE, R. F.; ROBINSON, N. E.; SLEIGHT, S. D. Definition of chemiluminescence and superoxide production responses of bovine neutrophils to selected soluble and particulate stimulants, and comparisons with the responses to Pasteurella haemolytica. American Journal of Veterinary Research, v. 56, n. 8, p. 1045-1054, 1995.

25.WERLING, D.; SILEGHEM, M.; LUTZ, H.; LANGHANS, W. Effect of bovine leukemia virus infection on bovine peripheral blood monocyte responsiveness to lipopolysaccharide stimulation in vitro. Veterinary Immunology and Immunopathology, v. 48, n. 1/2, p. 77-88, 1995.

26.PYEON, D.; O'REILLY, K. L.; SPLITTER, G. A. Increased interleukin-10 mRNA expression in tumor-bearing or persistently lymphocytotic animals infected with bovine leukemia virus. The Journal of Virology, v. 70, n. 8, p. 57065710, 1996.

27.YAKOBSON, B.; BRENNER, J.; UNGAR-WARON, H.; TRAININ, Z. Cellular immune response cytokine expression during the initial stage of bovine leukemia virus (BLV) infection determines the disease progression to persistent lymphocytosis. Comparative Immunology, Microbiology and Infectious Diseases, v. 23, n. 3, p. 197-208, 2000.

28. AMILLS, M.; RAMIYA, V.; NORIMINE, J.; COLLEEN, A.; OLMSTEAD, C. A. Reduced IL-2 and IL-4 mRNA expression in CD4+ $\mathrm{T}$ cells from bovine leukemia virus-infected cows with persistent lymphocytosis. Virology, v. 304, n. 1, p. 1-9, 2002.

29.DEBACQ, C.; ASQUITH, B.; REICHERT, M.; BURNY, A.; KETTMANN, R.; WILLEMS, L. Reduced cell turnover in bovine leukemia virus-infected, persistently lymphocytotic cattle. The Journal of Virology, v. 77, n. 24, p. 13073-13083, 2003.

30. KONNAI, S.; USUI, T.; IKEDA, M.; KOHARA, J.; HIRATA, T.; OKADA, K.; OHASHI, K.; ONUMA, M. Imbalance of tumor necrosis factor receptors during progression in bovine leukemia virus infection. Virology, v. 339, n. 2, p. 239-248, 2005.

31.KONNAI, S.; USUI, T.; IKEDA, M.; KOHARA, J.; HIRATA, T.; OKADA, K.; OHASHI, K.; ONUMA, M. Tumor necrosis factor-alpha up-regulation in spontaneously proliferating cells derived from bovine leukemia virus-infected cattle. Archives of Virology, v. 151, n. 2, p. 347-360, 2006.

32.KABEYA, H.; FUKUDA, A.; OHASHI, K.; SUGIMOTO, C.; ONUMA, M. Tumor necrosis factor alpha and its receptors in experimentally bovine leukemia virus-infected sheep. Veterinary Immunology and Immunopathology, v. 81, n. 1-2, p. 129-139, 2001.

33.BOUZAR, A. B.; BOXUS, M.; FLORINS, A.; FRANÇOIS, C.; REICHERT, M.; WILLEMS, L. Reduced levels of reactive oxygen species correlate with inhibition of apoptosis, rise in thioredoxin expression and increased bovine leukemia virus proviral loads. Retrovirology, v. 6, p. 102, 2009.

34.THANNICKAL, V. J.; FANBURG, B. L. Reactive oxygen species in cell signaling. American Journal of Physiology, v. 279 , n. 6, p. 1005-1028, 2000.

35. FREEMAN, B. A.; CRAPO, J. D. Biology of disease: free radicals and tissue injury. Laboratory Investigation, v. 47, n. 5, p. 412-426, 1982.

36.SCHAFER, F. Q.; BUETTNER, G. R. Redox environment of the cell as viewed through the redox state of the glutathione disulfide/glutathione couple. Free Radical Biology and Medicine, v. 30, n. 11, p. 1191-1212, 2001.

37.KEEFE, R. G.; CHOI, Y.; FERRICK, D. A.; STOTT, J. L. Bovine cytokine expression during different phases of bovine leukemia virus infection. Veterinary Immunology and Immunopathology, v. 56, n. 1-2, p. 39-51, 1997.

38. AMILLS, M.; NORIMINE, J.; OLMSTEAD, C. A.; LEWIN, H. A. Cytokine mRNA expression in B cells from bovine leukemia virus-infected cattle with persistent lymphocytosis. Cytokine, v. 28 , n. 1, p. 25-28, 2004.

39.PYO, C.-W.; LEE, S.-H.; CHOI, S.-Y. Oxidative stress induces PKR-dependent apoptosis via IFN-gamma activation signaling in Jurkat $\mathrm{T}$ cells. Biochemical and Biophysical Research Communications, v. 377, n. 3, p. 1001-1006, 2008. 